\title{
Prediction of the Laves Phase Morphology in Fe-Cr-W-C Quaternary Steels with the Aid of System Free Energy Concept
}

\author{
Yoshinori MURATA, Toshiyuki KOYAMA, ${ }^{1)}$ Masahiko MORINAGA and Toru MIYAZAKI') \\ Department of Materials Science and Engineering, Graduate School of Engineering, Nagoya University, Furo-cho, Chikusa-ku, \\ Nagoya 464-8603 Japan. $\quad$ 1) Computational Materials Science Center (CMSC), National Institute for Materials Science \\ (NIMS), Sengen, Tsukuba, Ibaraki 305-0047 Japan. $\quad 2$ 2) Emeritus Professor of Nagoya Institute of Technology, Gokiso-
} cho, Showa-ku, Nagoya 466-8555 Japan.

(Received on May 22, 2002; accepted in final form on August 26, 2002)

\begin{abstract}
In order to elucidate the microstructure evolution in advanced high $\mathrm{Cr}$ heat resisting ferritic steels, a timecomposition-temperature diagram of $\mathrm{Fe}-10$ mass $\% \mathrm{Cr}-\mathrm{W}-\mathrm{C}$ quaternary steels is calculated on the basis of the system free energy theory proposed by Koyama and Miyazaki. Microstructures of the steels are predictable using such a system free energy consisting of chemical free energy, interface energy and strain energy between the matrix and precipitates in the steels. In this study, our attention is focused on the Laves phase as the precipitate, because this phase is formed in recently developed heat resisting ferritic steels and affects their creep strength largely. The calculations conducted in the Fe-Cr-W-C quaternary steels lead to the following findings: (i) The Laves phase is not formed in those steels containing less than 0.4 mol\% W (about 1.4 mass\% W) even after a long term aging at 923K; (ii) Only granular Laves phase precipitates in the steel containing $0.4 \mathrm{~mol} \% \mathrm{~W}$ to $1.05 \mathrm{~mol} \% \mathrm{~W}$ (about $3.5 \mathrm{mass} \% \mathrm{~W}$ ) even in the early stage of aging at $923 \mathrm{~K}$; (iii) The morphological change of the Laves phase from the fine coherent precipitate to the granular one occurs in a regular aging sequence in the steel if it contains more than $1.05 \mathrm{~mol} \% \mathrm{~W}$; (iv) Coherent precipitation line for the Laves phase is determined in the quasi-binary phase diagram as a function of the $\mathrm{W}$ content. These findings obtained theoretically are consistent with experimental results.
\end{abstract}

KEY WORDS: ferritic steel; Laves phase; system free energy; microstructure evolution; TTT diagram.

\section{Introduction}

There has been a strong need to develop advanced ferritic steels which can be utilized even in the ultra super critical (USC) conditions of power plants. In those plants, there is a trend of raising the steam temperature up to $923 \mathrm{~K}$ $\left(650^{\circ} \mathrm{C}\right)$. Therefore it has been requested strongly to develop advanced high $\mathrm{Cr}$ ferritic steels which are tolerable in such severe operating conditions of power plants. High $\mathrm{Cr}$ heat resistant ferritic steels are composed generally of the martensite phase, $\mathrm{MX}$ carbonitride, $\mathrm{M}_{23} \mathrm{C}_{6}$ carbide and intermetallic compounds such as the Laves phase, the $\mu$ phase, the $z$ phase, etc. ${ }^{1,2)}$ As the microstructure in these steels is too complex, it is difficult to predict the microstructure evolution at high temperatures, although such a prediction is important in understanding creep strength of the ferritic steels.

In recent advanced heat resistant ferritic steels containing a large amount of refractory elements such as Mo, W, Re, etc., the Laves phase is believed to precipitate in the boundaries of martensite lath, block, packet and some prior austenite grains, while keeping granular in shape. However, a number of fine Laves-phase precipitates are found to exist even inside the martensite lath in the tempered steels of containing $10 \mathrm{mass} \% \mathrm{Cr}$ and $4.6 \mathrm{mass} \% \mathrm{~W}^{3}$ ) There is a room to debate on the contribution of the Laves phase to creep strength, but the fine Laves phase must contribute to the creep strength. Then it is important to make it clear the morphological change of the Laves phase for understanding the creep strength of these steels.

The objective of this study is to elucidate the microstructure evolution of the Laves phase in advanced high $\mathrm{Cr}$ heat resistant ferritic steels following the system free energy theory. ${ }^{4)}$ This is the first-step for predicting the whole microstructure evolution of high $\mathrm{Cr}$ ferritic steels.

\section{Theory of System Free Energy}

\subsection{System Free Energy for the $\mathrm{Fe}-\mathrm{Cr}-\mathrm{W}-\mathrm{C}$ System}

The total free energy of the microstructure should be given by the sum of a chemical free energy, $G_{0}$, an elastic strain energy, $E_{\text {str }}$, an interfacial energy contribution in the unit volume of the microstructure, $E_{\text {surf }}$, and an elastic interaction energy, $E_{\text {int }}$, and then a possibility of predicting the microstructure development is treatable on the basis of the total free energy. ${ }^{4)}$ Hereafter, $E_{\text {surf }}$ is called simply "interfacial energy". The total free energy is denoted as system free energy, $G_{\text {system }}\left(=G_{0}+E_{\text {str }}+E_{\text {surf }}+E_{\text {int }}\right)$.

The $\mathrm{Fe}-\mathrm{Cr}-\mathrm{W}-\mathrm{C}$ quaternary system is employed in order to perform the simulation of the advanced heat resisting steels, and special attention is directed towards the morphological evolution of the Laves phase. The existence of 
$\mathrm{M}_{23} \mathrm{C}_{6}$ carbide is also being considered in this simulation. But this carbide precipitates incoherently even in the astempered state in high $\mathrm{Cr}$ ferritic steel, and the morphological change of $\mathrm{M}_{23} \mathrm{C}_{6}$ carbide is smaller than that of the Laves phase. Therefore, the contribution of both elastic strain energy and interfacial energy generated from this carbide to the change of system free energy is disregarded in this study. Also, volume fractions of both the Laves phase and $\mathrm{M}_{23} \mathrm{C}_{6}$ carbide are small, and hence the interaction energy $E_{\text {int }}$ in $G_{\text {system }}$ is set to be zero in this simulation. Furthermore, MX type carbonitrides are not considered to influence the microstructure evolution of the Laves phase, because the carbonitrides scarcely change during aging at about $1000 \mathrm{~K}$ due to their high stability in the ferritic steels. As a result, the system free energy is estimated by the sum of chemical free energy, $G_{0}$, elastic strain energy, $E_{\text {str }}$, and interfacial energy, $E_{\text {surf }}$, in $\mathrm{Fe}-\mathrm{Cr}-\mathrm{W}-\mathrm{C}$ quaternary steels. In this case, the relationship between the microstructure evolution and the free energy change can be drawn as shown in Fig. 1.

Figure 1 is a schematic illustration of free energy changes during microstructure evolution in high $\mathrm{W}$ ferritic steels. Following the previous report, ${ }^{4)}$ the concept of system free energy is explained as follows. When the Laves phase precipitates from a supersaturated steel of the composition $X_{0}$, it has usually been considered that the free energy decreases to the equilibrium value, $G_{0}$. However, since the coherent precipitation of the Laves phase inevitably causes additional free energies such as elastic strain energy $E_{\text {str }}$ and an interfacial energy $E_{\text {surf }}$, the free energy of the microstructure is not $G_{0}$ but $G_{\text {system }}$. $G_{\text {system }}-G_{0}$ gradually decreases during the subsequent structural evolution such as the coarsening of the precipitates. Therefore it is expected
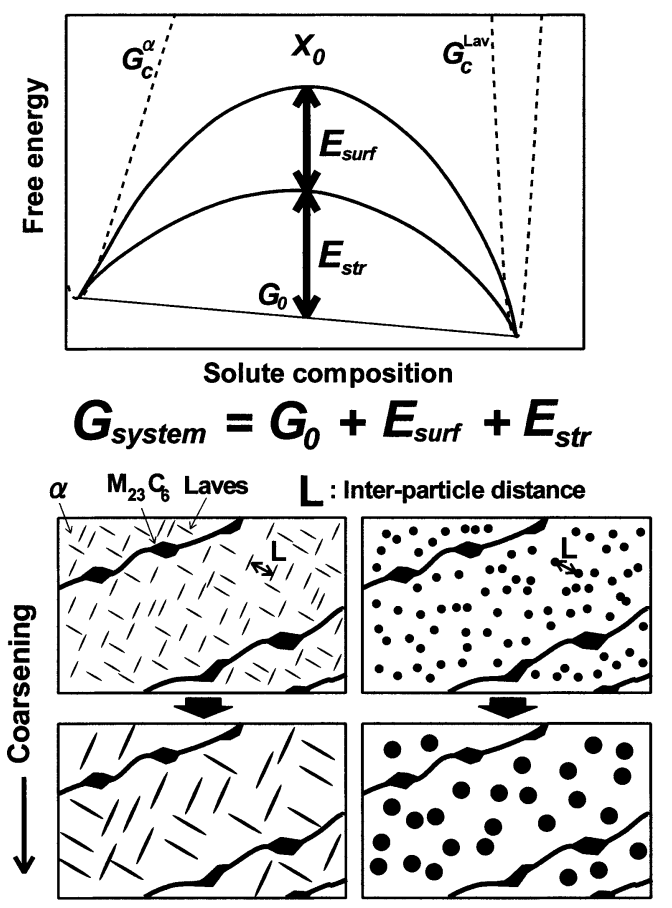

Fig. 1. Relationship between the free energy change and the microstructure evolution in $\mathrm{Fe}-\mathrm{Cr}-\mathrm{W}-\mathrm{C}$ steels. $E_{\text {surf }}$ is the interfacial energy in the unit volume and $E_{\text {str }}$ is the elastic strain energy. The free energy change is associated with the morphological change from the coherent fine Laves phase to the granular incoherent Laves phase. that the evaluation of $G_{\text {system }}$ in the progress should make it possible to predict the progress of microstructure evolution.

\subsection{Chemical Free Energy $G_{0}$ for $\mathrm{Fe}-\mathrm{Cr}-\mathrm{W}-\mathrm{C}$ Quaternary System}

The chemical free energy for $\mathrm{Fe}-\mathrm{Cr}-\mathrm{W}-\mathrm{C}$ alloys is evaluated as

$$
G_{0}=f_{\alpha} G^{\alpha}+f_{\mathrm{M}_{23} \mathrm{C}_{6}} G^{\mathrm{M}_{23} \mathrm{C}_{6}}+f_{\text {Laves }} G^{\text {Laves }}
$$

Here, $G_{0}, G^{\mathrm{M}_{23} \mathrm{C}_{6}}$ and $G^{\text {Laves }}$ are the chemical free energy for the $\alpha$ phase, for $\mathrm{M}_{23} \mathrm{C}_{6}$ carbide, and for the Laves phase, respectively. $f_{i}$ is the volume fraction of $i$ phase. Furthermore, $G^{\alpha}$ is separated into the following two parts, i.e., one is the paramagnetic term and the other is the term of ferromagnetic excess free energy.

$$
G^{\alpha}=\left[G^{\alpha}\right]^{\text {para }}+\left[\Delta G^{\alpha}\right]^{\text {ferro }}
$$

According to the sub-lattice model, $\left[G^{\alpha}\right]^{\text {para }}$ is expressed as

$$
\begin{gathered}
{\left[G^{\alpha}\right]^{\text {para }}=\frac{1}{a+c y_{\mathrm{C}}^{\mathrm{II}}}} \\
\times\left[\begin{array}{l}
y_{\mathrm{Va}}^{\mathrm{II}}\left(Y_{\mathrm{Fe}}^{\mathrm{I}}{ }^{\circ} G_{\mathrm{Fe}: \mathrm{Va}}^{\alpha}+Y_{\mathrm{Cr}}^{\mathrm{I}}{ }^{\circ} G_{\mathrm{Cr}: \mathrm{Va}}^{\alpha}+Y_{\mathrm{W}}^{\mathrm{I}}{ }^{\circ} G_{\mathrm{W}: \mathrm{Va}}^{\alpha}\right) \\
+y_{\mathrm{C}}^{\mathrm{II}}\left(Y_{\mathrm{Fe}}^{\mathrm{I}} G_{\mathrm{Fe}: \mathrm{C}}^{\alpha}+Y_{\mathrm{Cr}}^{\mathrm{I}}{ }^{\circ} G_{\mathrm{Cr}: \mathrm{C}}^{\alpha}+Y_{\mathrm{W}}^{\mathrm{I}}{ }^{\circ} G_{\mathrm{W}: \mathrm{C}}^{\alpha}\right) \\
+a\left\{\begin{array}{l}
Y_{\mathrm{Fe}}^{\mathrm{I}} Y_{\mathrm{Cr}}^{\mathrm{I}}\left(y_{\mathrm{Va}}^{\mathrm{II}} L_{\mathrm{Fe}, \mathrm{Cr}: \mathrm{Va}}^{\alpha}+y_{\mathrm{C}}^{\mathrm{II}} L_{\mathrm{Fe}, \mathrm{Cr}: \mathrm{C}}^{\alpha}\right) \\
+Y_{\mathrm{Fe}}^{\mathrm{I}} Y_{\mathrm{W}}^{\mathrm{I}}\left(y_{\mathrm{Va}}^{\mathrm{II}} L_{\mathrm{Fe}, \mathrm{W}: \mathrm{Va}}^{\alpha}+y_{\mathrm{C}}^{\mathrm{II}} L_{\mathrm{Fe}, \mathrm{W}: \mathrm{C}}^{\alpha}\right) \\
+Y_{\mathrm{Cr}}^{\mathrm{I}} Y_{\mathrm{W}}^{\mathrm{I}}\left(y_{\mathrm{Va}}^{\mathrm{II}} L_{\mathrm{Cr}, \mathrm{W}: \mathrm{Va}}^{\alpha}+y_{\mathrm{C}}^{\mathrm{II}} L_{\mathrm{Cr}, \mathrm{W}: \mathrm{C}}^{\alpha}\right)
\end{array}\right] \\
+c y_{\mathrm{Va}}^{\mathrm{II}} y_{\mathrm{C}}^{\mathrm{II}}\left(Y_{\mathrm{Fe}}^{\mathrm{I}} L_{\mathrm{Fe}: \mathrm{Va}, \mathrm{C}}^{\alpha}+Y_{\mathrm{Cr}}^{\mathrm{I}} L_{\mathrm{Cr}: \mathrm{Va}, \mathrm{C}}^{\alpha}+Y_{\mathrm{W}}^{\mathrm{I}} L_{\mathrm{W}: \mathrm{Va}, \mathrm{C}}^{\alpha}\right) \\
+a R T\left(Y_{\mathrm{Fe}}^{\mathrm{I}} \ln Y_{\mathrm{Fe}}^{\mathrm{I}}+Y_{\mathrm{Cr}}^{\mathrm{I}} \ln Y_{\mathrm{Cr}}^{\mathrm{I}}+Y_{\mathrm{W}}^{\mathrm{I}} \ln Y_{\mathrm{W}}^{\mathrm{I}}\right) \\
+c R T\left(y_{\mathrm{Va}}^{\mathrm{II}} \ln y_{\mathrm{Va}}^{\mathrm{II}}+y_{\mathrm{C}}^{\mathrm{II}} \ln y_{\mathrm{C}}^{\mathrm{II}}\right)
\end{array}\right] .
\end{gathered}
$$

Here, $a$ and $c$ are the number of sub-lattices for the substitutional sites and the number of sub-lattices for the interstitial sites, respectively. Va represents the atomic vacancy. $y_{\mathrm{Va}}^{\mathrm{II}}$ and $y_{\mathrm{C}}^{\mathrm{II}}$ are atomic fractions of vacancy and carbon in the sub-lattice II for interstitial elements, respectively. $Y_{i}^{\mathrm{I}}$ is the atomic fraction of $i$ element in the sub-lattice I for substitutional elements, ${ }^{\circ} G_{\mathrm{Xi}: \mathrm{Va}}^{\alpha}$ is the molar Gibbs energy for a $\left(\mathrm{X}_{i}\right)_{a}:(\mathrm{Va})_{c}$ type compound, ${ }^{\circ} G_{\mathrm{X}_{i}: \mathrm{C}}^{\alpha}$ is the molar Gibbs energy for a $\left(\mathrm{X}_{i}\right)_{a}:(\mathrm{C})_{c}$ type compound. Also, $L_{\mathrm{Fe}, \mathrm{X}_{i}: \mathrm{Va}}^{\alpha}$ is a molar interaction energy between $\mathrm{Fe}$ atom and $\mathrm{X}_{i}$ atom when all the sub-lattices for interstitial elements are occupied by vacancies, $L_{\mathrm{Fe}, \mathrm{X}_{i}: \mathrm{C}}^{\alpha}$ is a molar interaction energy between $\mathrm{Fe}$ atom and $\mathrm{X}_{i}$ atom when all the sub-lattices for interstitial elements are occupied by carbon atoms, and $L_{\mathrm{X}_{i}: \mathrm{Va}, \mathrm{C}}^{\alpha}$ is a molar interaction energy between carbon atom and vacancy when all the sub-lattices for substitutional elements are occupied by $\mathrm{X}_{i}$ atoms. $R$ is the gas constant and $T$ is the temperature. The molar Gibbs energy and the molar interaction energy are given in the Thermo-Calc database (see Appendix ${ }^{5,6)}$ ). Temperature dependence of the excess free energy associated with magnetic ordering is being considered using the formula proposed by Hillert and Jarl. ${ }^{7)}$

The chemical free energy of $\mathrm{M}_{23} \mathrm{C}_{6}$ is also calculated on the basis of the Thermo-Calc database using a formula of $(\mathrm{Fe}, \mathrm{Cr})_{20}(\mathrm{Fe}, \mathrm{Cr}, \mathrm{W})_{3} \mathrm{C}_{6},{ }^{8)}$ and then it is given as 


$$
\begin{aligned}
& G_{c}^{\mathrm{M}_{23} \mathrm{C}_{6}}=\frac{1}{29}
\end{aligned}
$$

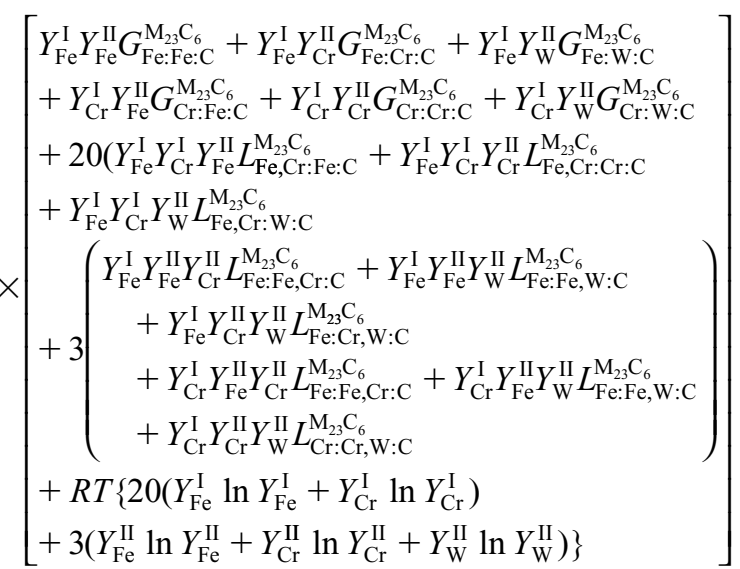

Also, according to the formula of $(\mathrm{Fe}, \mathrm{Cr})_{2} \mathrm{~W}$, chemical free energy for the Laves phase, $G_{c}^{\text {Laves }}$, is expressed as

$$
\begin{aligned}
G_{c}^{\mathrm{Laves}} \\
=\frac{1}{3}\left[\begin{array}{l}
Y_{\mathrm{Fe}}^{\mathrm{I}} Y_{\mathrm{W}}^{\mathrm{II}} G_{\mathrm{Fe}: \mathrm{W}}^{\mathrm{Laves}}+Y_{\mathrm{Cr}}^{\mathrm{I}} Y_{\mathrm{W}}^{\mathrm{II}} G_{\mathrm{Cr}: \mathrm{W}}^{\mathrm{Laves}}+2 Y_{\mathrm{Fe}}^{\mathrm{I}} Y_{\mathrm{Cr}}^{\mathrm{I}} Y_{\mathrm{W}}^{\mathrm{II}} L_{\mathrm{Cr}, \mathrm{Fe}: \mathrm{W}}^{\mathrm{Lave}} \\
\left.+R\left(Y_{\mathrm{Fe}}^{\mathrm{I}} \ln Y_{\mathrm{Fe}}^{\mathrm{I}}+Y_{\mathrm{Cr}}^{\mathrm{I}} \ln Y_{\mathrm{Cr}}^{\mathrm{I}}\right)+Y_{\mathrm{W}}^{\mathrm{II}} \ln Y_{\mathrm{W}}^{\mathrm{II}}\right\}
\end{array}\right] \\
=\frac{1}{3}\left[\begin{array}{l}
Y_{\mathrm{Fe}}^{\mathrm{I}} G_{\mathrm{Fe}: \mathrm{W}}^{\mathrm{Laves}}+Y_{\mathrm{Cr}}^{\mathrm{I}} G_{\mathrm{Cr}: \mathrm{W}}^{\mathrm{Laves}}+2 Y_{\mathrm{Fe}}^{\mathrm{I}} Y_{\mathrm{Cr}}^{\mathrm{I}} L_{\mathrm{Cr}, \mathrm{Fe}: \mathrm{W}}^{\mathrm{Laves}} \\
+2 R T\left(Y_{\mathrm{Fe}}^{\mathrm{I}} \ln Y_{\mathrm{Fe}}^{\mathrm{I}}+Y_{\mathrm{Cr}}^{\mathrm{I}} \ln Y_{\mathrm{Cr}}^{\mathrm{I}}\right)
\end{array}\right] \ldots \ldots \ldots . .(5)
\end{aligned}
$$

\subsection{Elastic Strain Energy for $\mathrm{Fe}-\mathrm{Cr}-\mathrm{W}-\mathrm{C}$ Quater- nary System}

In general, elastic strain energy is generated in the alloy when a coherent precipitate is dispersed in the matrix while having a different lattice constant from the matrix. From this sense, only the elastic strain energy generated from the coherent fine Laves phase is taken into account in $\mathrm{Fe}-\mathrm{Cr}-$ $\mathrm{W}-\mathrm{C}$ quaternary steels. The strain energy is given by

$$
\begin{aligned}
& E_{\text {str }}=A f(1-f)\left(c_{\text {Laves }}-c_{\alpha}\right)^{2} \eta^{2} Y_{\langle 100\rangle} \\
& Y_{\langle 100\rangle}=\frac{E}{1-v}
\end{aligned}
$$

Here, $A$ is a constant, and $f$ is the volume fraction of the precipitate. It is assumed that the elastic strain energy $E_{\text {str }}$ for the fine Laves phase to be about $20 \%$ of the value for the coherent precipitate in Fe-W binary system. ${ }^{9)}$ Then $A$ is set to be 0.2 in this simulation. $c_{\text {Laves }}$ and $c_{\alpha}$ are chemical compositions of the Laves phase and the ferrite phase, respectively. $\eta\left(c_{\text {Laves }}-c_{\alpha}\right)$ is the eigen strain between the $\alpha$ phase and the Laves phase in the coherent plane. ${ }^{10)} E$ and $v$ are the Young's modulus and the Poisson's ratio, respectively, and the values of pure iron as shown below are used in this study.

$$
\begin{aligned}
& E: 1.9 \times 10^{11} \mathrm{~Pa}, \\
& v: 0.185 .
\end{aligned}
$$

\subsection{Interfacial Energy for $\mathrm{Fe}-\mathrm{Cr}-\mathrm{W}-\mathrm{C}$ Quaternary System}

The interfacial energy $E_{\text {surf }}$ between the Laves phase and the matrix is evaluated in both coherent and incoherent states by using the following equation.

$$
E_{\text {surf }}=S_{V}(p) \gamma_{\mathrm{S}} V_{\mathrm{m}}
$$

where $S_{V}(p)$ is interfacial area per unit volume and $V_{\mathrm{m}}$ is the molar volume. Also, $S_{V}(p)$ is expressed as

$$
\begin{aligned}
S_{V}(p) & =\frac{S(p)}{V}=\frac{S(p)}{V_{p}\left\{\left(p\left(r_{0}\right)\right\} / f\right.} \\
& =\frac{f \pi r_{0}^{2} p^{-2 / 3}[2+g(p)]}{\frac{4}{3} \pi r_{0}^{3}}=\frac{3 f p^{-2 / 3}[2+g(p)]}{4 r_{0}} \ldots
\end{aligned}
$$

Here, $V$ is a volume of the steel, $f$ is the volume fraction of the precipitate, $r_{0}$ is a radius of the sphere having the same volume of ellipsoid of the aspect ratio, $p$, and $V_{p}\left\{p\left(r_{0}\right)\right\}$ is the volume of the precipitate. $g(p)$ is a function representing a shape of ellipsoid. There are three possible types of $g(p)$ depending on the aspect ratio of $p$, and they are represented as

$$
\begin{array}{ll}
g(p)=\frac{2 p^{2}}{\left(1-p^{2}\right)^{1 / 2}} \log \left[\frac{1+\left(1-p^{2}\right)^{1 / 2}}{p}\right] & (p<1) \\
g(p)=2 & (p=1) \\
g(p)=\frac{2 p^{2}}{\left(p^{2}-1\right)^{1 / 2}} \tan ^{-1}\left(p^{2}-1\right)^{1 / 2} & (p>1)
\end{array}
$$$$
(p=1)
$$

In Eq. (7), the surface interfacial energy, $\gamma_{S}$, and the aspect ratio, $p$, are set to be the following values in this study.

(i) for the fine Laves phase: $\gamma_{\mathrm{S}}=\gamma_{\mathrm{c}}=0.1 \mathrm{~J} / \mathrm{m}^{2}$, and $p=0.1$,

(ii) for the granular Laves phase: $\gamma_{\mathrm{S}}=\gamma_{\mathrm{i}}=0.468 \mathrm{~J} / \mathrm{m}^{2}$, and $p=1$.

Here, $\gamma_{c}$ and $\gamma_{i}$ are the coherent- and the incoherent-interface energy, respectively. This incoherent-interfacial energy, $\gamma_{\mathrm{i}}$, is the value for the grain-boundary energy-density of the $\delta$ phase. ${ }^{9}$ )

\section{Results and Discussion}

\subsection{Calculated Results}

Figure 2(a) shows the changes in the system free energy at $923 \mathrm{~K}$ with the size of the Laves phase in an $\mathrm{Fe}-$ $10 \mathrm{mass} \% \mathrm{Cr}-9.35 \mathrm{mass} \%(3 \mathrm{~mol} \%) \mathrm{W}-0.11 \mathrm{mass} \% \mathrm{C}$ steel (notice: W coordinate shown in Fig. 2 is represented in mol\%). The three horizontal lines in the figure correspond to three energy levels, which are the free energy of the supersaturated solid solution of $3 \mathrm{~mol} \% \mathrm{~W}$ steel $\left(G_{\mathrm{c}}^{\alpha}\right)$, the free energy of the microstructure precipitating the coherent Laves phase $\left(G_{0}+E_{\text {str }}^{\text {coh }}+E_{\text {surf }}\right)$, and the free energy of the microstructure precipitating the incoherent Laves phase $\left(G_{0}+E_{\text {str }}^{\text {inch }}\right)$. In Fig. 2(a), the full line represents the case of coherent Laves phase and the broken line shows the case of the incoherent (granular) Laves phase. When the size is small, the system free energy for the fine coherent Laves phase is lower than that for the incoherent one. The critical size of the coherent-to-incoherent transition is estimated from Fig. 2(a) to be about $7 \mathrm{~nm}$ for the $3 \mathrm{~mol} \% \mathrm{~W}$ steel. It is noted here that this value is a radius of the sphere having the same volume of ellipsoid of an aspect ratio, $p$. Therefore, when the shape is ellipsoidal, the long diameter of the 
ellipsoid is much larger than the critical value shown in Fig. 2.

A series of calculations similar to Fig. 2(a) is carried out using steels with various $\mathrm{W}$ contents. As a result, Fig. 2(b) is obtained. This figure exhibits the stable morphology of
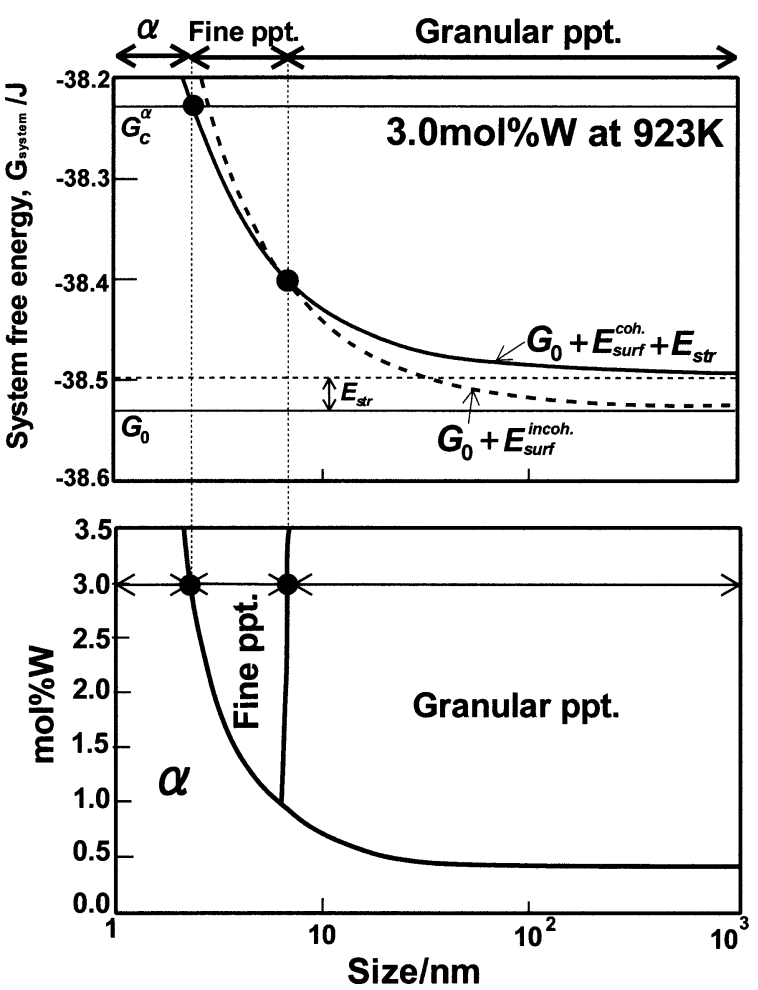

Fig. 2. (a) Changes in the system free energy at $923 \mathrm{~K}$ with the size of the Laves phase in an $\mathrm{Fe}-10$ mass $\% \mathrm{Cr}-$ $9.35 \mathrm{mass} \%(3 \mathrm{~mol} \%) \mathrm{W}-0.11 \mathrm{mass} \% \mathrm{C}$ steel. (b) Stable morphology of the Laves phase in $\mathrm{Fe}-10 \mathrm{Cr}-\mathrm{W}-$ $0.11 \mathrm{C}(\mathrm{mass} \%)$ quaternary steels. (notice: $\mathrm{W}$ coordinate shown in $\mathrm{mol} \%$ ) the Laves phase at $923 \mathrm{~K}$ in $\mathrm{Fe}-10 \mathrm{Cr}-\mathrm{W}-0.11 \mathrm{C}(\operatorname{mass} \%)$ quaternary steels. In this figure, the phase boundary between the coherent and the granular Laves phases at 3 mol\% W corresponds to the critical size shown in Fig. 2(a). In Fig. 2, the size scale is able to convert into the time scale following the equation, $r^{m}-r_{\mathrm{t}=0}^{m}=k t$, where $k$ and $m$ are constants and $r_{t=0}$ is the size at $t=0$.

Figure 3 shows the calculated results exhibiting the stable morphology of the Laves phase which changes with the $\mathrm{W}$ content, the size and the temperature in $\mathrm{Fe}-10 \mathrm{Cr}-$ $\mathrm{W}-0.11 \mathrm{C}$ (mass\%) alloys. Three bottom figures show stable regions for the coherent and the granular (incoherent) Laves phases at 900, 1000 and $1100 \mathrm{~K}$. These calculated results lead to the following findings: (i) The Laves phase is not formed in those steels containing less than $0.4 \mathrm{~mol} \% \mathrm{~W}$ (about 1.4 mass $\% \mathrm{~W}$ ) even after a long term aging at $923 \mathrm{~K}$; (ii) Only granular Laves phase precipitates in the steel containing $0.4 \mathrm{~mol} \% \mathrm{~W}$ to $1.05 \mathrm{~mol} \% \mathrm{~W}$ (about $3.5 \mathrm{mass} \% \mathrm{~W}$ ) even in the early stage of aging at $923 \mathrm{~K}$; (iii) The morphological change of the Laves phase from the fine coherent precipitate to the granular one occurs in a regular aging sequence at $923 \mathrm{~K}$ in the steel containing more than 1.05 $\mathrm{mol} \% \mathrm{~W}$.

A series of calculations similar to the bottom figures in Fig. 3 is conducted at various temperatures. As a result, a quasi-binary phase diagram for the Laves phase is obtained as shown in the upper figures of Fig. 3. It is found that the critical $\mathrm{W}$ concentration at which the Laves phase changes the shape from fine to granular one increases with increasing temperature. The fine coherent Laves phase exists in the region of the higher $\mathrm{W}$ contents and the lower temperatures in this quasi-binary phase diagram.

\subsection{Comparison between the Calculated Results and Experimental Results}

In the upper figures of Fig. 3, experimental data are also
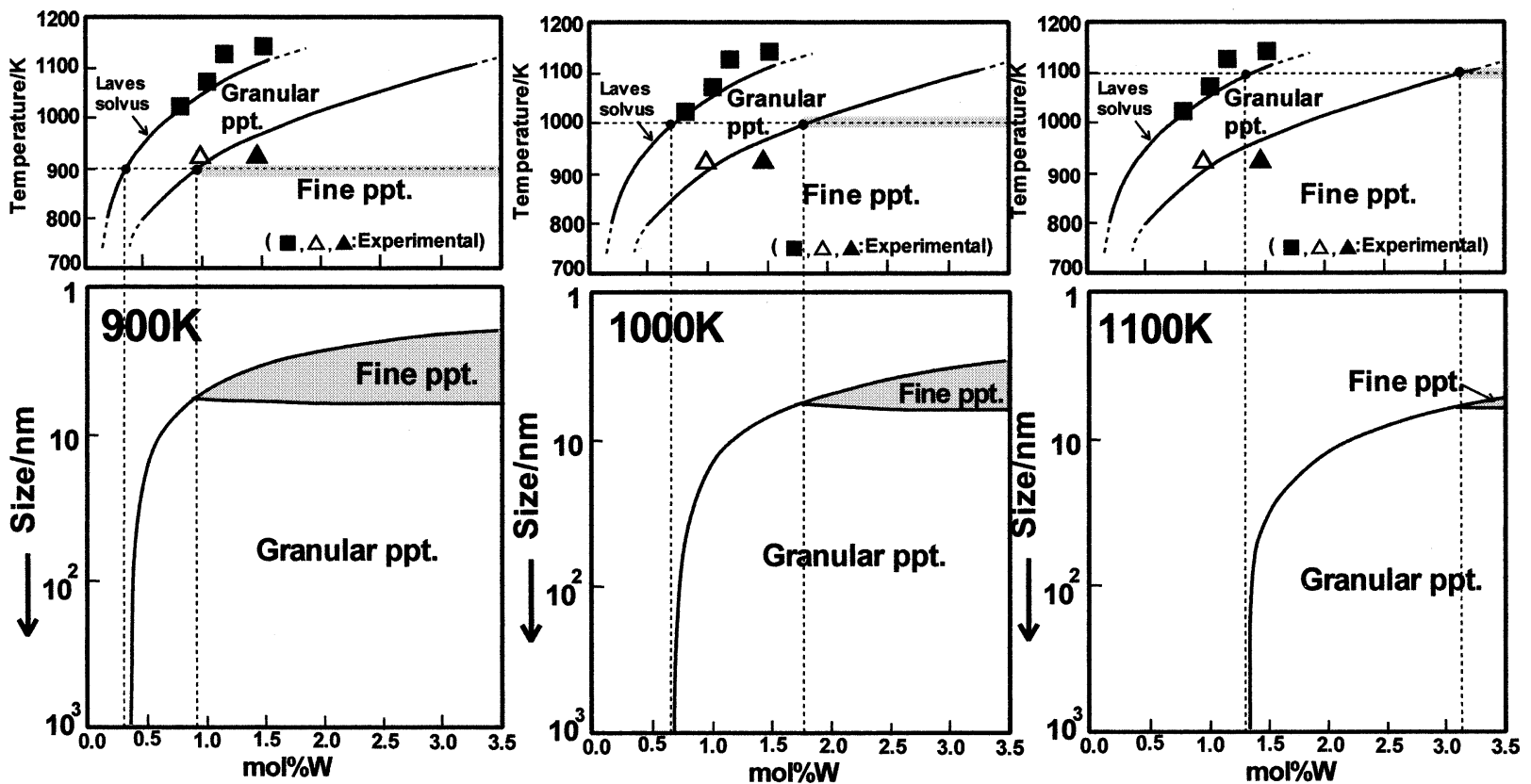

Fig. 3. Calculated results exhibiting the stable morphology of the Laves phase in $\mathrm{Fe}-10 \mathrm{mass} \% \mathrm{Cr}-\mathrm{W}-\mathrm{C}$ quaternary steels. Square and triangle marks plotted in the upper figures are experimental results. The open triangles and solid triangles show the positions where the granular Laves phase and the fine coherent Laves phase are observed, respectively. 

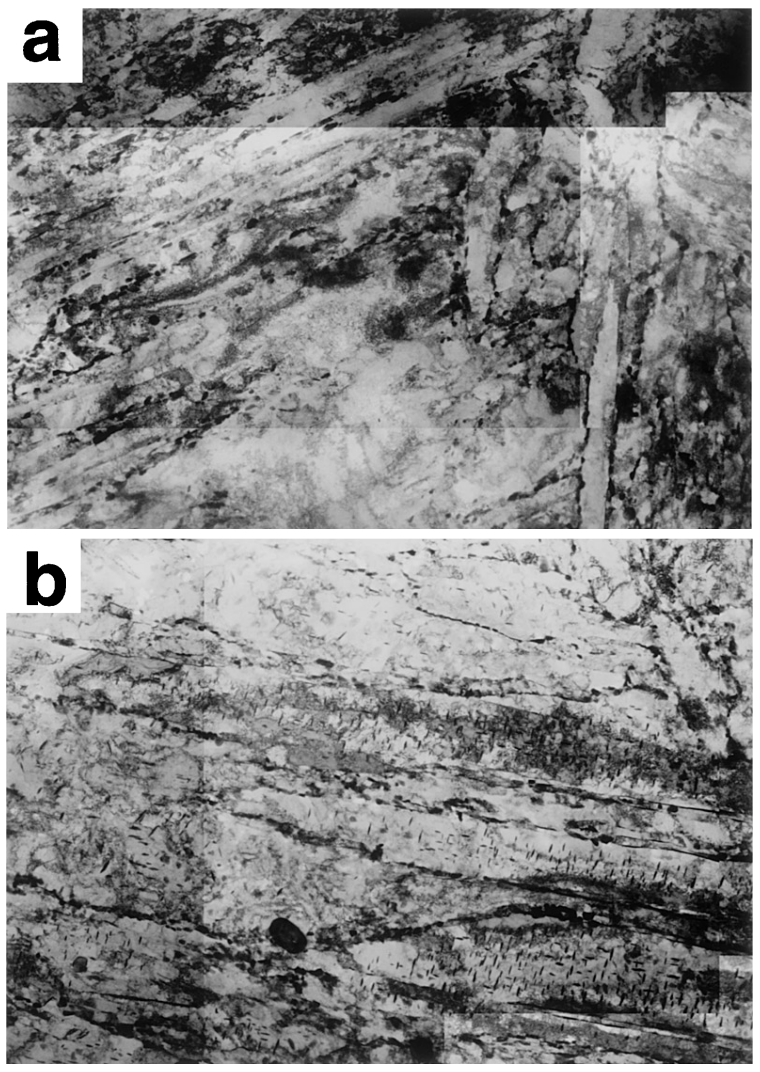

$\overline{2 \mu \mathrm{m}}$

Fig. 4. TEM micrographs in the as-tempered state for (a) $\mathrm{Fe}-10 \mathrm{Cr}-0.11 \mathrm{C}-3.0 \mathrm{~W}-\mathrm{Co}-\mathrm{V}-\mathrm{Mo}$ steel, and (b) $\mathrm{Fe}-$ $10 \mathrm{Cr}-0.11 \mathrm{C}-4.6 \mathrm{~W}-\mathrm{Co}-\mathrm{V}-\mathrm{Mo}$ steel (mass\%).

plotted using square and triangle marks which are obtained at $923 \mathrm{~K}$ in $\mathrm{Fe}-10 \mathrm{Cr}-0.11 \mathrm{C}-\mathrm{W}-\mathrm{Co}-\mathrm{V}-\mathrm{Mo}(\operatorname{mass} \%)$ ferritic steels. The square marks show the solid-solubility for the Laves phase. On the other hand, the open triangle and solid triangles show the positions, where the granular Laves phase and the fine coherent Laves phase are observed, respectively. Typical TEM microstructures taken from $\mathrm{Fe}-$ $10 \mathrm{Cr}-0.11 \mathrm{C}-\mathrm{W}-\mathrm{Co}-\mathrm{V}-\mathrm{Mo}$ (mass\%) steels in the as-tempered state ${ }^{3)}$ are shown in Fig. 4. The steel shown in (a), contains $3.0 \mathrm{mass} \% \mathrm{~W}(0.93 \mathrm{~mol} \% \mathrm{~W})$ corresponding to the open triangle, whereas the steel shown in (b), contains 4.6 mass $\% \mathrm{~W}(1.42 \mathrm{~mol} \% \mathrm{~W})$ corresponding to the solid triangle. It is found that the fine precipitates of the Laves phase are observed within the martensite lath in the steel shown in (b), but no fine precipitates in the steel shown in (a). By comparing these experimental data with the calculated phase boundaries, it is found that the coherent precipitation lines predicted by the system free energy agrees well with the experimental results.

Figure 5 shows a TEM micrograph of the extraction replica taken from $\mathrm{Fe}-10 \mathrm{Cr}-0.12 \mathrm{C}-1.9 \mathrm{~W}-\mathrm{Co}-\mathrm{V}-0.4 \mathrm{Mo}$ (mass\%) steel aged at $923 \mathrm{~K}$ for $0.36 \mathrm{Ms}(100 \mathrm{~h})$ after quenching into water from $1323 \mathrm{~K}$ followed by sub-zero treatment using liquid nitrogen. Form EDX analysis as well as the selected area diffraction, it is found that the fine particles observed in the martensite lath boundaries in Fig. 5 are $\mathrm{M}_{23} \mathrm{C}_{6}$ carbide and the large granular precipitates are the Laves phase. In this case, the Laves phase precipitates as

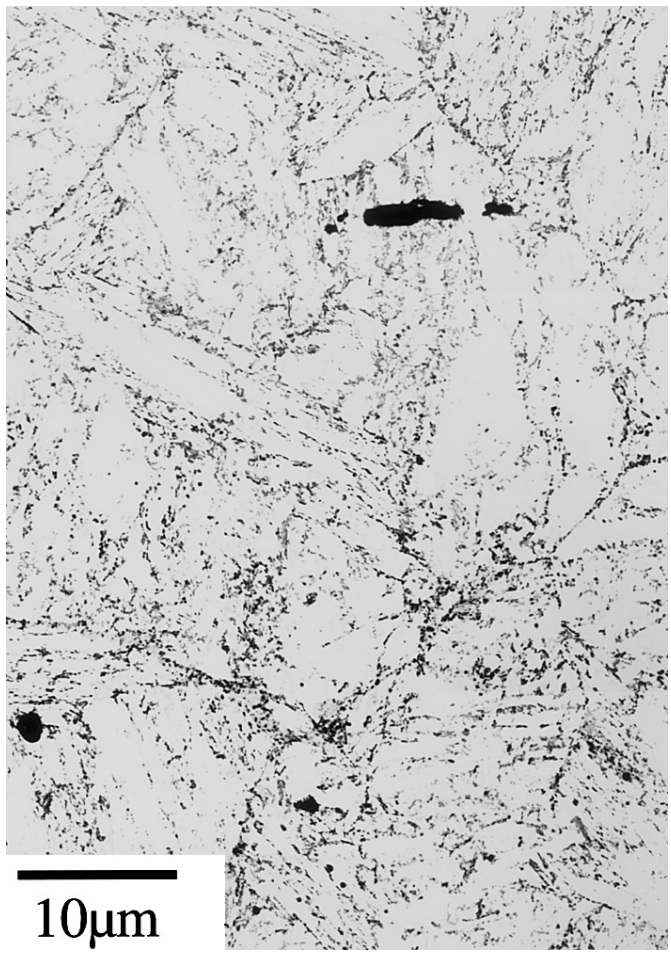

Fig. 5. TEM micrograph of the extraction replica taken from $\mathrm{Fe}-10 \mathrm{Cr}-0.12 \mathrm{C}-1.9 \mathrm{~W}-\mathrm{Co}-\mathrm{V}-0.4 \mathrm{Mo}$ (mass\%) steel aged at $923 \mathrm{~K}$ for $0.36 \mathrm{Ms}(100 \mathrm{~h})$ after quenching into water from $1323 \mathrm{~K}$ followed by the sub-zero treatment.
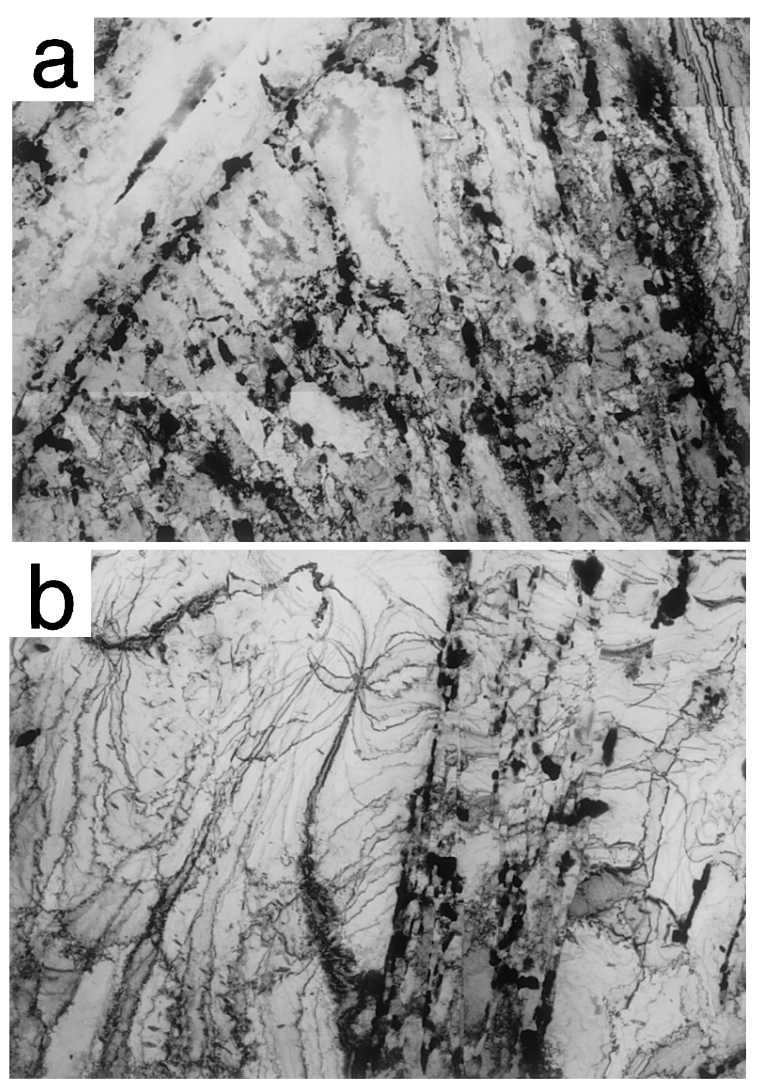

$\overline{2 \mu m}$

Fig. 6. TEM micrographs in aged state at $923 \mathrm{~K}$ taken from (a) $\mathrm{Fe}-10 \mathrm{Cr}-0.11 \mathrm{C}-3.0 \mathrm{~W}-\mathrm{Co}-\mathrm{V}-\mathrm{Mo}$ steel aged for 9.072 $\mathrm{Ms}$, and (b) $\mathrm{Fe}-10 \mathrm{Cr}-0.11 \mathrm{C}-4.6 \mathrm{~W}-\mathrm{Co}-\mathrm{V}-\mathrm{Mo}$ steel aged for $14.39 \mathrm{Ms}$. 
the granular phase with several microns in size, and the amount is very small. Total amount of $\mathrm{Mo}+\mathrm{W}$ in this steel is $0.81 \mathrm{~mol} \%(2.3 \mathrm{mass} \%)$, which corresponds to the composition within the solubility limit of the Laves phase at $923 \mathrm{~K}$ but very near the limit, as shown in the upper figures of Fig. 3. As is known generally, the particle size becomes large near the solubility limit of the precipitates. The experimental result shown in Fig. 5 is consistent with the calculated solubility limit for the Laves phase shown in Fig. 3.

As shown in Fig. 4, the morphology of the precipitated Laves phase depends on the $\mathrm{W}$ content in the steel. After aging at $923 \mathrm{~K}$, however, the Laves phase becomes granular in both the steels shown in Fig. 6. In other words, the granular Laves phase precipitates in $\mathrm{Fe}-10 \mathrm{Cr}-0.11 \mathrm{C}-3.0$ mass $\%(0.93 \mathrm{~mol} \%) \mathrm{W}-\mathrm{Co}-\mathrm{V}-\mathrm{Mo}$ steel, without precipitating the fine coherent Laves phase. This phenomenon is understood since the $0.93 \mathrm{~mol} \% \mathrm{~W}$ corresponds to the composition lying between the solubility limit and the coherent precipitation line for the Laves phase at $923 \mathrm{~K}$, resulting in no precipitation of the fine coherent Laves phase in any time, i.e., in any size (see Fig. 3). The experimental results shown in Fig. 4 and Fig. 6 agree well with the calculated results shown in Fig. 3.

The system-free-energy calculations supported by a few experimental results will serve as a powerful method for predicting the microstructure evolution in high $\mathrm{Cr}$ ferritic steels with complicated microstructures.

\section{Conclusions}

The concept of system free energy is applied to the prediction of the morphological change of the Laves phase in high $\mathrm{Cr}$ ferritic steels containing W. It is shown that the critical $\mathrm{W}$ concentration for the transition from coherent-to-incoherent Laves phase in the $\mathrm{Fe}-\mathrm{Cr}-\mathrm{W}-\mathrm{C}$ system is predicted on the basis of the system free energy. Coherent precipitation line for the Laves phase is determined in the quasibinary phase diagram as a function of the $\mathrm{W}$ content. The prediction from the system free energy agrees well with the experimental results of high $\mathrm{Cr}$ heat resistant ferritic steels.

\section{Acknowledgement}

This work is supported in part by the Grant-in-Aid for Scientific Research of Japan Society for the Promotion of Science (JSPS), Japan.

\section{REFERENCES}

1) T. Fujita: ISIJ Int., 32 (1992), 175.

2) A. Strang and V. Vodarek: Mater. Sci., Technol., 12 (1996), 552.

3) Y. Murata, M. Morinaga, R. Hashizume, K. Takami, T. Azuma, Y. Tanaka and T. Ishiguro: Mater. Sci. Eng., A282 (2000), 251.

4) T. Miyazaki and T. Koyama: Mater. Sci. Eng., A136 (1991), 151.

5) Thermo-Calc ver. M, Foundation for Computational Thermodynamics, Stockholm, Sweden, (1995).

6) N. Saunders and A. P. Miodownik; CALPHAD (Calculation of Phase Diagram): A Comprehensive guide, Pergamon, London, UK, (1998).

7) M. Hillert and M. Jarl: Calphad, 2 (1978), 227.

8) P. Custafson: Metall. Trans. A, 19A (1988), 2547.

9) T. Koyama: Doctoral Thesis, Nagoya Institute of Technology, Nagoya, (1996),

10) Y. Murata, T. Takami, M. Kamiya, M. Morinaga, R. Hashizume, K. Miki, T. Azuma and T. Ishiguro; Tetsu-to-Hagané, 88 (2002), 214.

11) L. E. Murr: Interfacial Phenomena in Metals and Alloys, AddisonWesley Publishing Co. Inc., London, UK, (1975), 131

\section{Appendix}

Thermodynamic data used in this study is given by the Thermo-Calc database. ${ }^{5}$ ) They are shown below. The meaning of variables is followed by the text book of CALPHAD. ${ }^{6}$

$$
\begin{aligned}
& \text { Bcc } \_ \text {A2 } \\
& G_{\mathrm{Cr}: \mathrm{C}}^{\alpha}-3 H_{\mathrm{Gra}}^{\mathrm{SER}}-H_{\mathrm{Cr}}^{\mathrm{SER}} \\
& \quad=+\mathrm{GHSERCR}+3 \mathrm{GHSERCC}+416000 \\
& G_{\mathrm{Fe}: \mathrm{C}}^{\alpha}-3 H_{\mathrm{Gra}}^{\mathrm{SER}}-H_{\mathrm{Fe}}^{\mathrm{SER}} \\
& \quad=+\mathrm{GHSERFE}+3 \mathrm{GHSERCC}+322050+75.667 * T \\
& G_{\mathrm{W}: \mathrm{C}}^{\alpha}-3 H_{\mathrm{Gra}}^{\mathrm{SER}}-H_{\mathrm{W}}^{\mathrm{SER}} \\
& \quad=+\mathrm{GHSERWW}+3 \mathrm{GHSERCC}+375100-35.87 * T \\
& G_{\mathrm{Cr}: \mathrm{Va}}^{\alpha}-H_{\mathrm{Cr}}^{\mathrm{SER}}=+\mathrm{GHSERCR} \\
& G_{\mathrm{Fe}: \mathrm{Va}}^{\alpha}-H_{\mathrm{Fe}}^{\mathrm{SER}}=+\mathrm{GHSERFE} \\
& G_{\mathrm{W}: \mathrm{Va}}^{\alpha}-H_{\mathrm{W}}^{\mathrm{SER}}=+\mathrm{GHSERWW} \\
& T_{\mathrm{C}}^{\alpha}=-331.5 x_{\mathrm{Cr}}+1043 x_{\mathrm{Fe}}+\left\{1650+550\left(x_{\mathrm{Cr}}-x_{\mathrm{Fe}}\right)\right\} x_{\mathrm{Cr}} x_{\mathrm{Fe}} \\
& \beta^{\alpha}=-0.01 x_{\mathrm{Cr}}+2.22 x_{\mathrm{Fe}}-0.85 x_{\mathrm{Cr}} x_{\mathrm{Fe}} \\
& L_{\mathrm{Cr}, \mathrm{Fe}: \mathrm{C}}^{\alpha}=-1250000+667.7 * T \\
& L_{\mathrm{Cr}, \mathrm{Fe}: \mathrm{Va}}^{\alpha}=+20500-9.68 * T \\
& L_{\mathrm{Fe}, \mathrm{W}: \mathrm{C}}^{\alpha}=-140000 \\
& L_{\mathrm{Fe}, \mathrm{W}: \mathrm{Va}}^{\alpha}=+41544-12621\left(Y_{\mathrm{Fe}}^{\mathrm{I}}-Y_{\mathrm{W}}^{\mathrm{I}}\right) \\
& L_{\mathrm{Cr}, \mathrm{W}: \mathrm{Va}}^{\alpha}=+31520-1320\left(Y_{\mathrm{Cr}}^{\mathrm{I}}-Y_{\mathrm{W}}^{\mathrm{I}}\right) \\
& L_{\mathrm{Cr}: \mathrm{C}, \mathrm{Va}}^{\alpha}={ }^{0} L_{\mathrm{Fe}: \mathrm{C}, \mathrm{Va}}^{\mathrm{bcc}}=-190 * T \\
&
\end{aligned}
$$

\section{Laves phase}

$$
\begin{aligned}
& G_{\mathrm{Cr}: \mathrm{W}}^{\mathrm{Laves}}-2 H_{\mathrm{Cr}}^{\mathrm{SER}}-H_{\mathrm{W}}^{\mathrm{SER}}=+2 \mathrm{GCRFCC}+\mathrm{GHSERWW} \\
& -359-7.2 * T \\
& G_{\mathrm{Fe}: \mathrm{W}}^{\mathrm{Laves}}-2 H_{\mathrm{Cr}}^{\mathrm{SER}}-H_{\mathrm{W}}^{\mathrm{SER}}=+2 \mathrm{GFEFCC}+\mathrm{GHSERWW} \\
& -13500+5 * T \\
& L_{\mathrm{Cr}, \mathrm{Fe}: \mathrm{W}}^{\mathrm{Laves}}=-12500 \\
& \mathrm{M}_{23} \mathrm{C}_{6} \\
& G_{\mathrm{Cr}: \mathrm{Cr}: \mathrm{C}}^{\mathrm{M}_{2} \mathrm{C}_{6}}-6 H_{\mathrm{Gra}}^{\mathrm{SER}}-23 H_{\mathrm{Cr}}^{\mathrm{SER}}=+\mathrm{GCRM} 23 \mathrm{C} 6 \\
& G_{\mathrm{Fe}: \mathrm{Cr}: \mathrm{C}}^{\mathrm{M}_{23} \mathrm{C}_{6}}-6 H_{\mathrm{Gra}}^{\mathrm{SER}}-3 H_{\mathrm{Cr}}^{\mathrm{SER}}-20 H_{\mathrm{Fe}}^{\mathrm{SER}} \\
& =+.1304348 * \text { GCRM23C } 6+.8695652 * \text { GFEM23C6 } \\
& G_{\mathrm{Cr}: \mathrm{Fe}: \mathrm{C}}^{\mathrm{M}_{23} \mathrm{C}_{6}}-6 H_{\mathrm{Gra}}^{\mathrm{SER}}-20 H_{\mathrm{Cr}}^{\mathrm{SER}}-3 H_{\mathrm{Fe}}^{\mathrm{SER}} \\
& =+.8695652 * \text { GCRM23C } 6+.1304348 * \text { GFEM23C6 } \\
& G_{\mathrm{Fe}: \mathrm{Fe}: \mathrm{C}}^{\mathrm{M}_{23} \mathrm{C}_{6}}-6 H_{\mathrm{Gra}}^{\mathrm{SER}}-23 H_{\mathrm{Fe}}^{\mathrm{SER}}=+ \text { GFEM23C6 } \\
& G_{\mathrm{Cr}: \mathrm{W}: \mathrm{C}}^{\mathrm{M}_{23} \mathrm{C}_{6}}-6 H_{\mathrm{Gra}}^{\mathrm{SER}}-20 H_{\mathrm{Cr}}^{\mathrm{SER}}-3 H_{\mathrm{W}}^{\mathrm{SER}} \\
& =+.8695652 * \text { GCRM } 23 \mathrm{C} 6+3 * \text { GHSERWW } \\
& +.7826087 * \text { GHSERCC }+18850-75.4 * T \\
& G_{\mathrm{Fe}: \mathrm{W}: \mathrm{C}}^{\mathrm{M}_{23} \mathrm{C}_{6}}-6 H_{\mathrm{Gra}}^{\mathrm{SER}}-20 H_{\mathrm{Fe}}^{\mathrm{SER}}-3 H_{\mathrm{W}}^{\mathrm{SER}} \\
& =+.8695652 * \text { GFEM23C } 6+3 * \text { GHSERWW } \\
& +.7826087 * \text { GHSERCC }-103240+38.4 * T
\end{aligned}
$$


